\title{
Reconstructed heterograft aortic valves for human use
}

\section{Preparation and surgical implantation for mitral, aortic, and tricuspid replacement}

\author{
MARIAN I. IONESCU, YEHIA A. S. MASHHOUR, AND \\ GEOFFREY H. WOOLER
}

From the Department of Thoracic Surgery, The General Infirmary at Leeds and Leeds University

The technique of preparing prosthetic aortic heterologous valves for clinical use is outlined in detail, and the surgical implantation of these grafts into the mitral, aortic, and tricuspid areas is described. Between February and December 1967, 42 such grafts have been inserted into 41 patients with good results up to 10 months since the operation. No systemic emboli have occurred although anticoagulants have not been used for more than four to six weeks postoperatively.

The possibility of replacing heart valves with reconstructed heterografts has recently been demonstrated (Ionescu, Wooler, Smith, and Grimshaw, 1967 ; Ionescu, Stoker, and Wooler, 1968 ; Wooler and Ionescu, 1968).

In Leeds, altogether 42 prosthetic heterologous aortic valves have been inserted into 41 patients between February and December 1967. The immediate and short-term results are encouraging. The details of clinical use and the results in patients operated upon have been reported (Ionescu, 1968 ; Ionescu, Wooler, Grimshaw, and Smith, 1968 ; Wooler and Ionescu, 1967a, b, and c).

Replacement of the mitral valve with a prosthetic aortic heterograft has proved to be a simple surgical procedure, and so we have used the same technique for the aortic and tricuspid valves.

The purpose of this paper is to outline step by step the technique of preparation and surgical implantation of prosthetic aortic heterografts when replacing the mitral, aortic, and tricuspid human valves.

\section{PREPARATION OF THE GRAFTS}

COLLECTION AND DISSECTION OF THE VALVES The aortic valves are taken from pigs 1 to 2 years old and weighing between 150 and $300 \mathrm{~kg}$. The hearts are collected without sterile precautions immediately after slaughter and are brought to the laboratory. The dissection and trimming of the aortic valve is per- formed during the subsequent few hours. All connective tissue and myocardium are removed except for a layer of muscle, 1 to $3 \mathrm{~mm}$. thick, which is left covering part of the right coronary cusp. The aorta is divided about 3 to $4 \mathrm{~mm}$. above the insertion of the commissures, and a rim of tissue, $2 \mathrm{~mm}$. wide, is left below the sinuses of Valsalva.

The mitral valve is divided 4 to $5 \mathrm{~mm}$. from the insention of the aortic cusp, thus providing a rim of strong tissue to be attached to the support.

The inside and outside diameters of the valve are now measured at both the ventricular and aortic ends. The inside diameter is measured with a conical obturator, taking care not to distend the lumen. The outside diameter is measured with callipers. These results are recorded.

The valve is then placed in cold saline. Valves may be safely kept in saline at $2^{\circ}$ to $4^{\circ} \mathrm{C}$. for 24 hours without undergoing deleterious changes in structure or tensile strength. We prefer to mount them on to the appropriate support immediately after the dissection has been completed. The sizes of the pig valves necessary to cater for all human requirements range from $14 \mathrm{~mm}$. to $34 \mathrm{~mm}$. internal diameter.

CONSTRUCTION OF THE SUPPORTS Two different types of support are used to hold the aortic heterografts in position. ${ }^{1}$

The first was designed to be used only in the mitral annulus. The second was designed for the aortic and tricuspid positions, but it was found to be equally suitable for the mitral annulus. It is more easily constructed than the first type, and during the past

1Commercially available from Hypodermic Services, 45 Hare Park Lane, Hightown, Liversedge, Yorks 
six months we have used only this second type of support for all three positions.

First type (Fig. 1) This consists of a knitted Teflon tube large enough to enclose the graft. The auricular end of this tube contains a semi-rigid Teflon ring, $3 \mathrm{~mm}$. thick and 30 to $42 \mathrm{~mm}$. internal diameter. The other end (ventricular); which will later be sutured to the mitral annulus, contains a titanium ring, $1 \mathrm{~mm}$. thick and 26 to $38 \mathrm{~mm}$. internal diameter.

Second type (Figs 2 and 3) This is a thin-walled titanium ring with three legs, entirely covered both

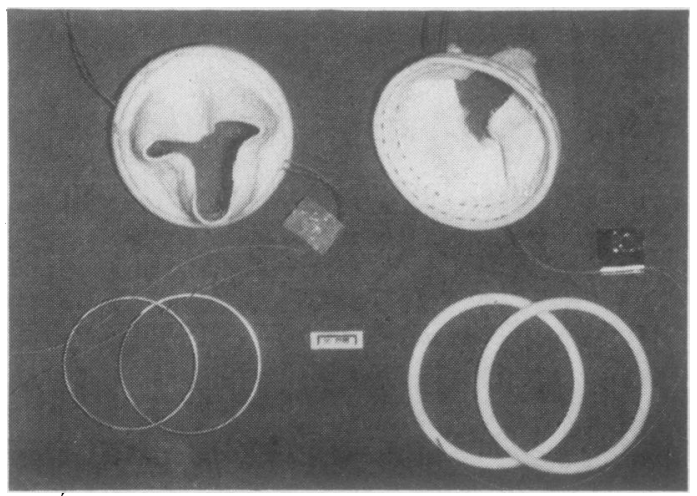

FIG. 1. Knitted Teflon tubes containing a semi-rigid Teflon ring at the auricular end. The titanium rings shown at bottom left will be fixed to the ventricular end of the Teflon support.

inside and outside with Dacron velour. ${ }^{2}$ On the outer circumference of this ring a Dacron felt ring covered with the same piece of velour cloth provides strong anchorage for suturing (Fig. 4).

Sizes from $30 \mathrm{~mm}$. to $40 \mathrm{~mm}$. internal diameter are available for the mitral and tricuspid positions.

The titanium ring angulates outwards $30^{\circ}$ to its attached legs for the mitral and tricuspid positions. This angle is reduced to $15^{\circ}$ for aortic replacement, otherwise it will not fit into the aortic root. The sizes available for sub-coronary insertion vary from $18 \mathrm{~mm}$. to $28 \mathrm{~mm}$. internal diameter.

The position of the legs on the titanium ring should correspond exactly to the position of the commissures in the graft. In order to obtain this information we dissected and measured the aortic valves in more than 150 pig hearts. Recording these measurements enabled us to establish the size and shape of the whole range of titanium frames which would be required, from the smallest aortic frame $(18 \mathrm{~mm}$.) to the largest tricuspid frame $(40 \mathrm{~mm}$.).

We found that in the majority of pigs the right and left coronary cusps are almost exactly the same

2U.S.C.I. Corp., Glens Falls, N.Y., U.S.A.-Dacron velour No. 6108: Dacron felt No. 6075

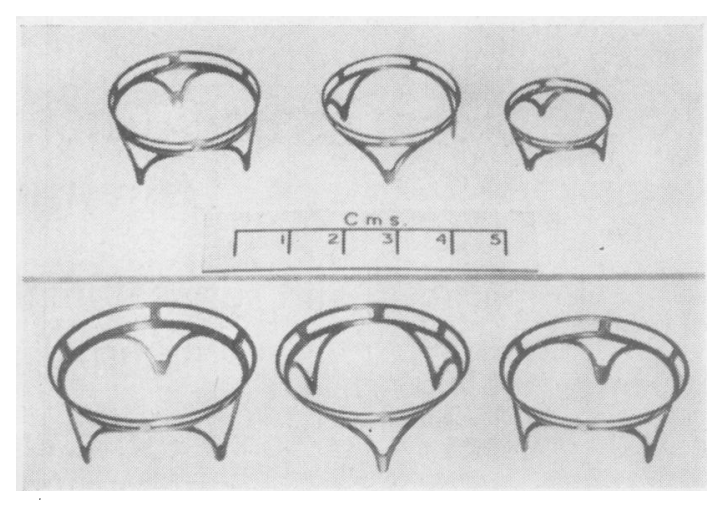

FIG. 2. Thin-walled titanium rings for aortic (top row) ando mitral and tricuspid (bottom row) replacement.

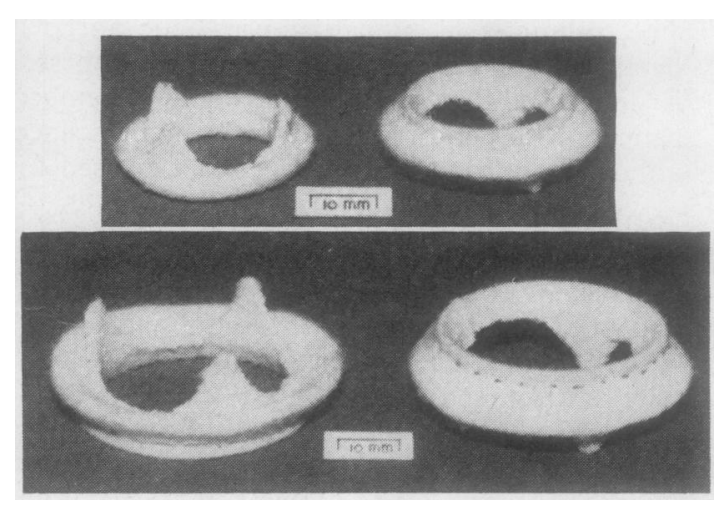

FIG. 3. Titanium rings covered with Dacron velour. The suturing rim is reinforced inside with Dacron felt.

size, whereas the non-coronary cusp is always smaller.

The Table describes the details of the titanium frames which are necessary for insertion into every을 size of human valve annulus.

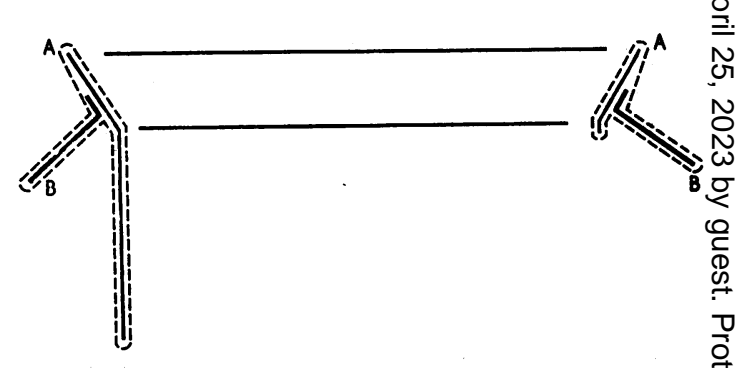

FIG. 4. Schematic view of the titanium ring $(A)$ covered with Dacron velour (dotted line) and the suturing rim containing Dacron felt $(B)$. The whole structure, titanium and Dacron felt are covered with the same piece of velour cloth (dotted line). 
T A B L E

TITANIUM FRAME ${ }^{1}$

\begin{tabular}{|c|c|c|c|c|c|c|c|}
\hline 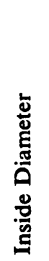 & 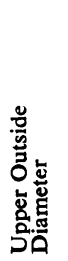 & 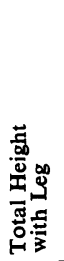 & 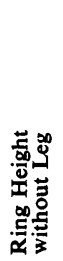 & 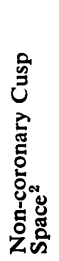 & 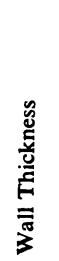 & 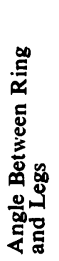 & 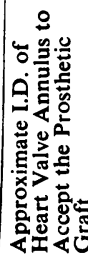 \\
\hline $\begin{array}{l}16 \\
18 \\
20 \\
22\end{array}$ & $\begin{array}{l}18 \\
20 \\
22 \\
24\end{array}$ & $\begin{array}{c}9 \\
10 \cdot 5 \\
11 \cdot 5 \\
12 \cdot 5\end{array}$ & $\begin{array}{l}2 \\
2 \\
2 \\
2 \cdot 5\end{array}$ & $\begin{array}{l}2 \cdot 5 \\
3 \\
3 \cdot 5 \\
4\end{array}$ & $\begin{array}{l}0.55 \\
0.55 \\
0.55 \\
0.55\end{array}$ & $\begin{array}{l}15^{\circ} \\
115^{\circ} \\
15^{\circ} \\
15^{\circ}\end{array}$ & $\begin{array}{l}20-21 \\
22-23 \\
24-25 \\
26-27\end{array}$ \\
\hline $\begin{array}{l}24 \\
26 \\
28\end{array}$ & $\begin{array}{l}26 \\
28 \cdot 5 \\
30 \cdot 5\end{array}$ & $\begin{array}{l}14 \\
15 \\
16\end{array}$ & $\begin{array}{l}3 \\
3 \\
3 \cdot 5\end{array}$ & $\begin{array}{l}4 \cdot 5 \\
5 \\
5 \cdot 5\end{array}$ & $\begin{array}{l}0.65 \\
0.65 \\
0.65\end{array}$ & $\begin{array}{l}15^{\circ} \\
15^{\circ} \\
15^{\circ}\end{array}$ & $\begin{array}{l}28-29 \\
30-31 \\
32-33\end{array}$ \\
\hline $\begin{array}{l}30 \\
32 \\
34\end{array}$ & $\begin{array}{l}35 \\
37 \\
39\end{array}$ & $\begin{array}{l}17 \cdot 5 \\
18 \cdot 5 \\
19 \cdot 5\end{array}$ & $\begin{array}{l}4 \\
4 \\
4 \cdot 5\end{array}$ & $\begin{array}{l}6 \\
6 \cdot 5 \\
7\end{array}$ & $\begin{array}{l}0.75 \\
0.75 \\
0.75\end{array}$ & $\begin{array}{l}30^{\circ} \\
30^{\circ} \\
30^{\circ}\end{array}$ & $\begin{array}{l}33-34 \\
35-36 \\
37-38\end{array}$ \\
\hline $\begin{array}{l}36 \\
38 \\
40\end{array}$ & $\begin{array}{l}41 \\
43 \\
45\end{array}$ & $\begin{array}{l}21 \\
22 \\
23\end{array}$ & $\begin{array}{l}5 \\
5 \\
5\end{array}$ & $\begin{array}{l}7 \cdot 5 \\
8 \\
8 \cdot 5\end{array}$ & $\begin{array}{l}0.85 \\
0.85 \\
0.85\end{array}$ & $\begin{array}{l}30^{\circ} \\
30^{\circ} \\
30^{\circ}\end{array}$ & $\begin{array}{l}39-40 \\
41-42 \\
43-44\end{array}$ \\
\hline
\end{tabular}

${ }^{1}$ Titanium-160.

${ }^{2}$ This figure to be subtracted from one-third of the circumference for the non-coronary cusp space, and half this figure to be added to each of the other two-thirds for the coronary cusp spaces.

Sizes are given in millimetres.

ATTACHING GRAFTS TO THEIR SUPPORTS AND METHOD OF STERILIZATION The correct size of dissected valve is chosen to fit exactly into the prosthetic support so that it is not deformed. We have found that the aortic valve functions properly only if its shape is maintained as near as possible to the normal.

Using the first type of support, nearly all the aortic wall, which forms the three sinuses of Valsalva, is cut away, leaving only a rim of aortic wall, $2 \mathrm{~mm}$. wide, attached to the insertion of the aortic cusps. The sinuses of Valsalva are then replaced with Dacron felt, using a continuous suture of 4-0 Mersilene (Fig. 5). The reconstructed aortic sinuses are carefully and tightly packed with cotton-wool soaked in formaldehyde. This is an essential step for perfect coaptation of the leaflets over a surface of at least 3 to $5 \mathrm{~mm}$. and maintenance of the shape of the sinuses. The graft is soaked in a $4 \%$ formaldehyde solution buffered at a pH of 5.6 (Moeys, Mreyen, and Den Hartog, 1954) for at least two weeks. The graft is then sutured inside the tube of Teflon to which the two rings have already been attached. Interrupted sutures are used to join the lower part of the graft (ventricular aspect), while at the upper part of the graft on the aortic side a continuous suture joins the Dacron felt to the knitted Teflon tube (Fig. 6). The completed prosthetic graft is replaced in the formaldehyde solution until it is required.

The $p \mathrm{H}$ of the solution is checked at the end of the first, second, and third weeks. If necessary, the solution is changed. The $p H$ appears to remain stabilized after three weeks, so that no further checks are necessary. We assume that this is due to the small amount of tissue in contact with the formaldehyde.

If the second type of support is chosen, which is Dacron-covered titanium frame, the aortic wall is removed in a similar way to that already described. The apex of each commissure of the graft is trimmed in both width and breadth in order to mould it correctly to the apex of each leg on the supporting frame.

We have found that the inside diameter of an aortic valve graft is 6 to $8 \mathrm{~mm}$. less than the inside diameter of the supporting frame.

Example The internal diameter of a freshly dissected graft, which measures $24 \mathrm{~mm}$. at the ventricular end, will become $26 \mathrm{~mm}$. after removal of the aortic wall forming the sinuses, and $28 \mathrm{~mm}$. under physiological distension. This same graft will measure $32 \mathrm{~mm}$. outside diameter and will fit perfectly into a frame of $32 \mathrm{~mm}$. internal diameter.

Each cusp is measured around its circumference. The left and right coronary cusps should be equal, whereas the non-coronary cusp should be approximately $25 \%$ smaller than the other two. The majority of pig aortic valves have this size ratio of the cusps. The others are unfit for fixation on to a supporting frame and are discarded.

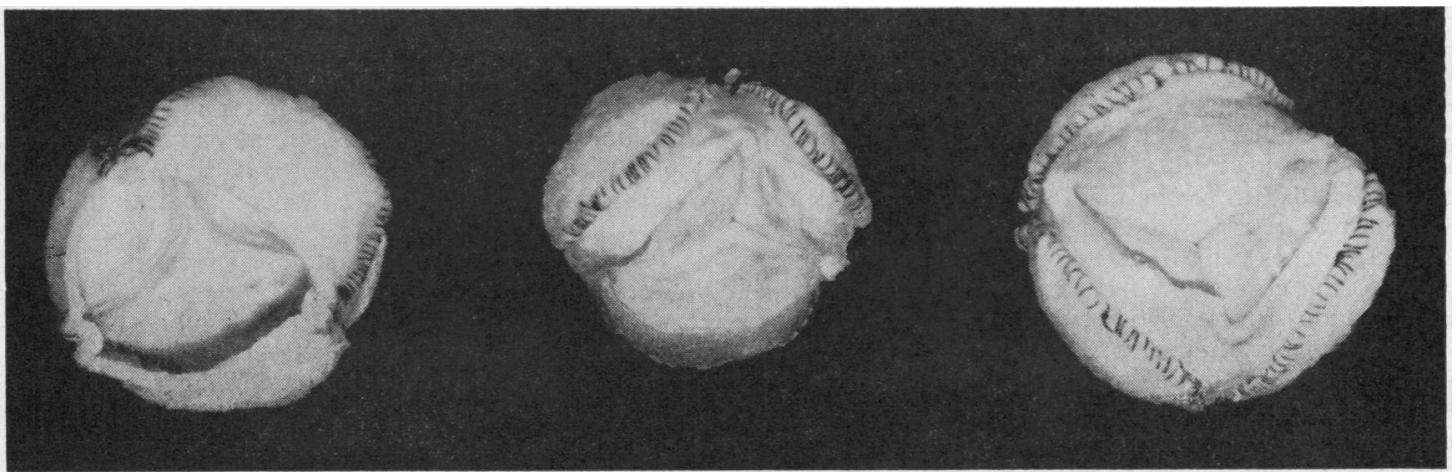

FIG. 5. Aortic heterografts with the sinuses of Valsalva removed and replaced with Dacron felt. 


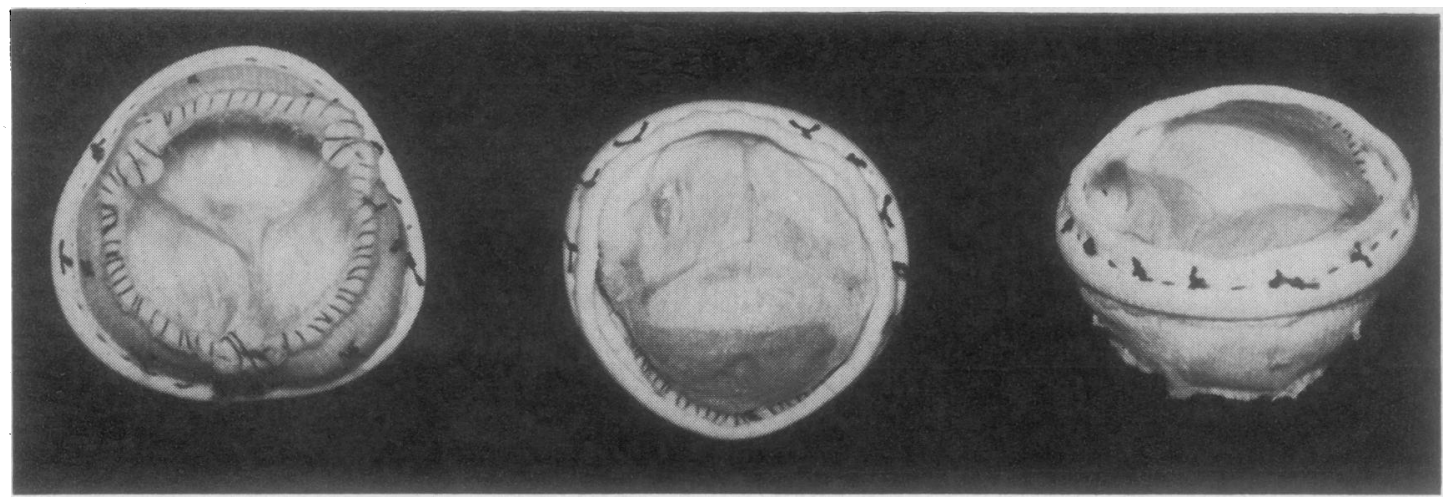

FIG. 6. Aortic heterografts reconstructed with Dacron felt and sutured inside the Teflon tubes to which the Teflon and titanium rings have already been attached.

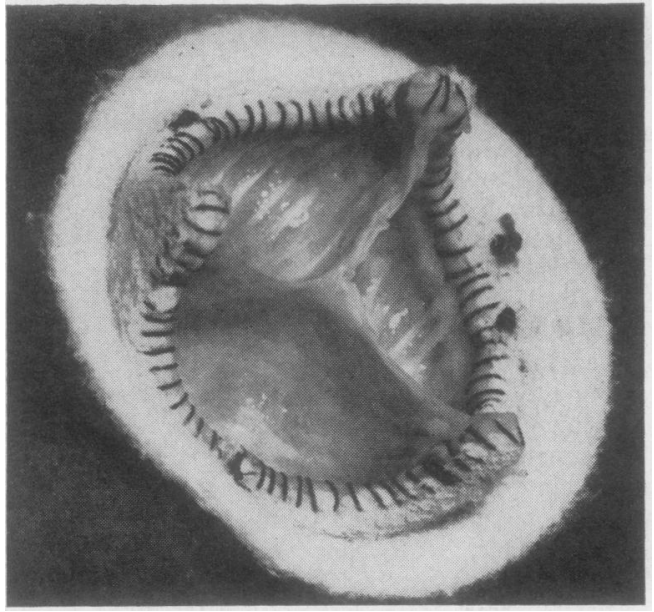

FIG. 7. Aortic heterograft sutured to a Dacron velourcovered titanium support seen from the aortic side of the graft.

The correct frame is chosen after accurate measurements of the graft have been obtained. The scallopedshape aortic margin of the graft is sutured to the Dacron velour-covered frame using a continuous 4-0 Mersilene suture, after which the cusps are carefully packed with cotton-wool soaked in formaldehyde in order to retain their shape (Fig. 7). A few interrupted stitches will hold the ventricular side of the graft to the corresponding margin of the frame while a continuous suture is inserted along the undersurface of the left and non-coronary cusps incorporating a remnant of the mitral valve for strengthening this suture line (Fig. 8). The muscular portion of the right coronary cusp is reinforced by suturing Dacron velour tightly from the superior margin of the frame to the endocardium of this cusp (Fig. 9). Thus a small

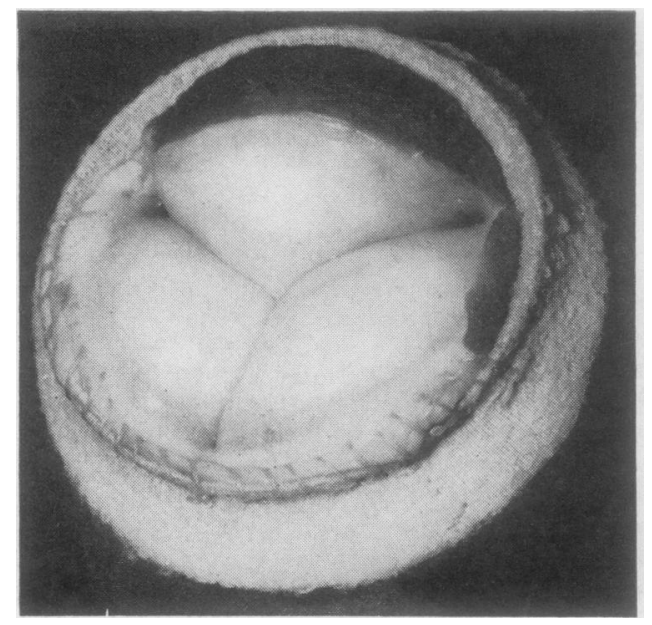

FIG. 8. Aortic heterograft sutured to a Dacron velourcovered titanium support seen from the ventricular side of the graft.

sling is constructed for this part of the valve which, $N$ inside the pig's heart, is supported by ventricular wall.

For aortic replacement the grafts are prepared in the same way, except that they are trimmed more on $\omega$ the outside of the sinuses to provide a thinner walled $O$ valve which will have a larger central opening (Fig. 10).

The graft mounted on its supporting frame is stored in formalin for at least two to three weeks.

PREPARATION OF GRAFTS FOR SURGERY The day before operation the correct prosthetic heterografts are chosen according to whioh valve is being changed and the size of the heart. Usually two different sizes are prepared for mitral valve replacement, four for an aortic, and one or two for the tricuspid valve. 


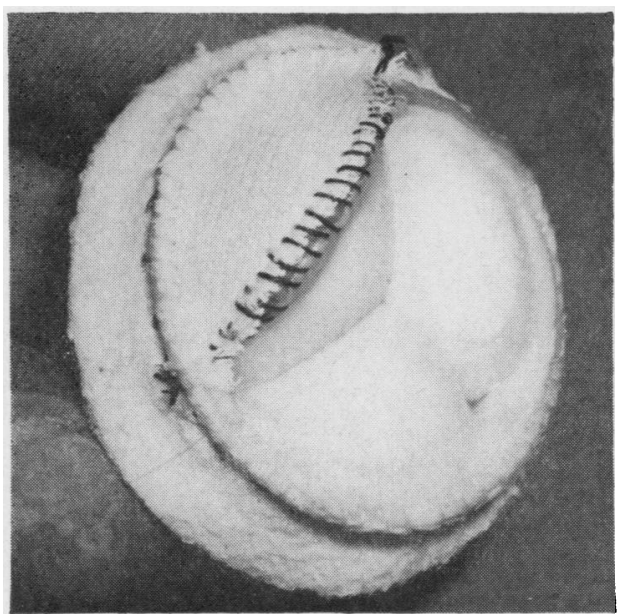

FIG. 9. The same view as in Fig. 8. The muscular part of the right coronary cusp is covered with Dacron cloth.

The selected grafts are washed thoroughly two or three times in large amounts of saline and left to soak in 2 litres of heparinized saline for 8 to 10 hours before implantation in order to remove as much formalin as possible. During the last hour the saline is changed and heparin and antibiotics are added (50 units $/ \mathrm{ml}$. heparin, $100 \mathrm{units} / \mathrm{ml}$. penicillin, and 0.2 g./ litre streptomycin).

If the first type of graft, supported with a semirigid Teflon ring, is being used the interrupted mattress sutures with double needles may be placed into position before thoracotomy is performed. Between 14 and 16 No. 1 Mersilene double-needle sutures are inserted through the aortic end of the prepared heterograft from inside, and they include the thin titanium ring. Three sutures are placed across the commissures over a small Dacron patch to prevent cutting through the aortic tissue (Fig. 11). The needles are fixed in order

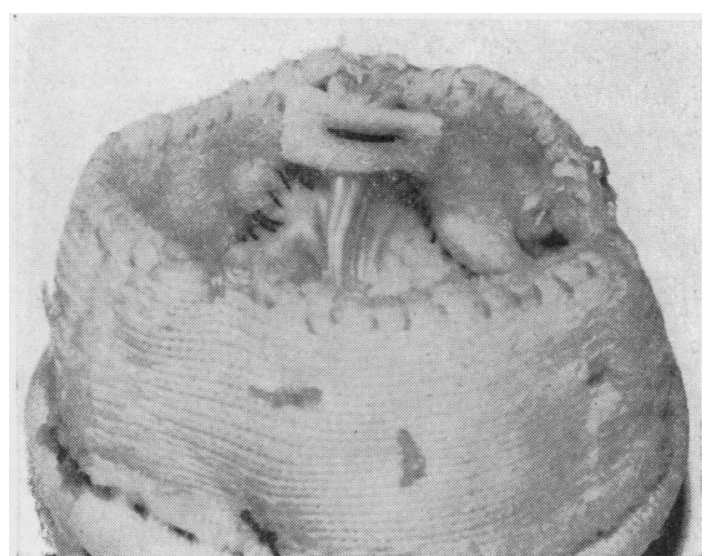

FIG. 11. Aortic heterograft supported with a semi-rigid Teflon ring. The suture placed across the commissure is reinforced with a Dacron patch.

on three small towels to facilitate manipulation, and the heterograft is left in heparinized saline with antibiotics.

\section{OPERATIVE TECHNIQUE}

MITRAL VALVE REPLACEMENT We prefer to work with the heart beating and a vent needle in the aorta in order to prevent air emboli. The diseased mitral valve is excised, leaving a 3-mm. rim of cusp tissue. If the mural cusp is neither calcified nor distorted with disease it may be left in place together with its chordae and papillary muscles.

The inside diameter of the mitral annulus is then measured with obturators and the correct size of heterograft is chosen.

1. The first type of graft with the semi-rigid Teflon ring is inserted into the mitral area using a double layer of sutures (Fig. 12). The right coronary

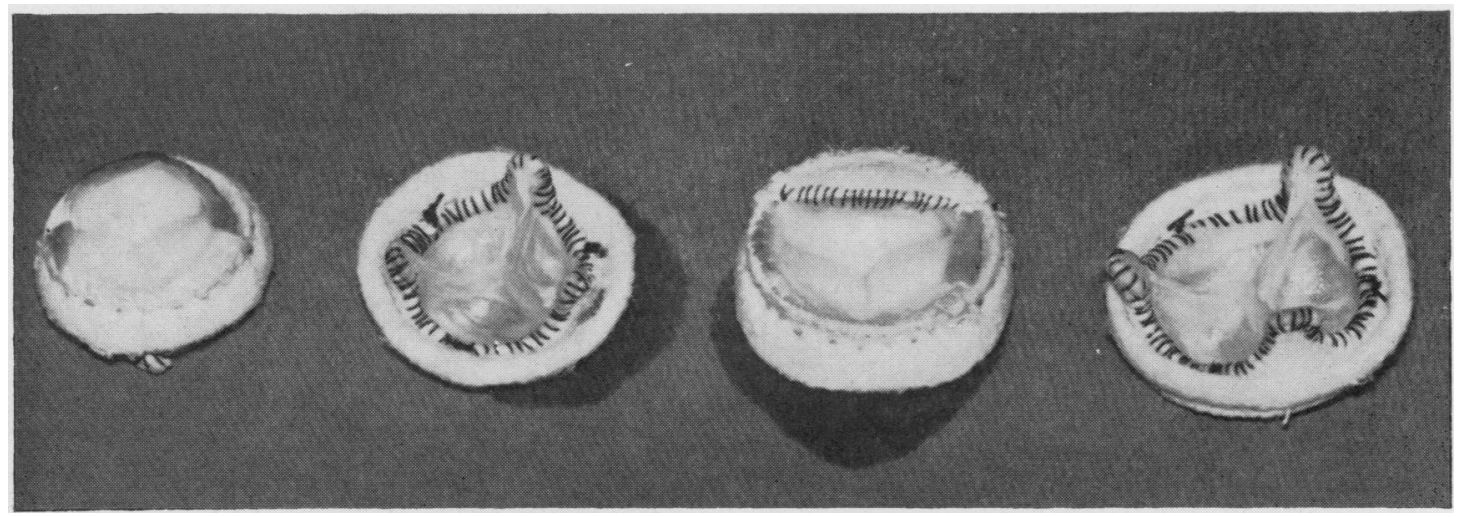

FIG. 10. Prosthetic heterografts for aortic replacement (from left to right, 20, 22, 24, and 26 mm. inside diameter). 


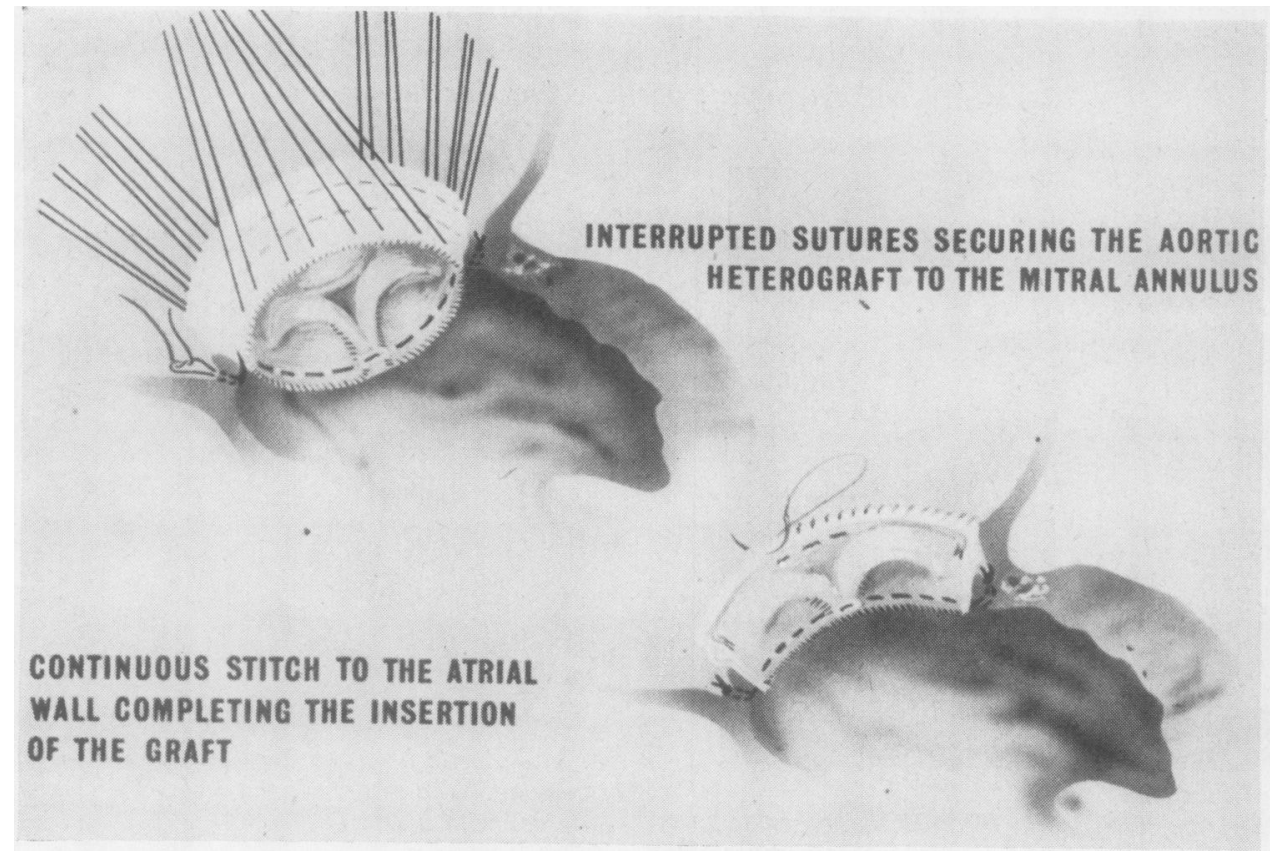

FIG. 12. Schematic representation of insertion technique into the mitral position of an aortic heterograft supported with a semi-rigid Teflon ring. Interrupted mattress sutures are used to secure the aortic end of the graft to the mitral annulus. A continuous stitch will attach the ventricular end of the graft to the auricular wall.

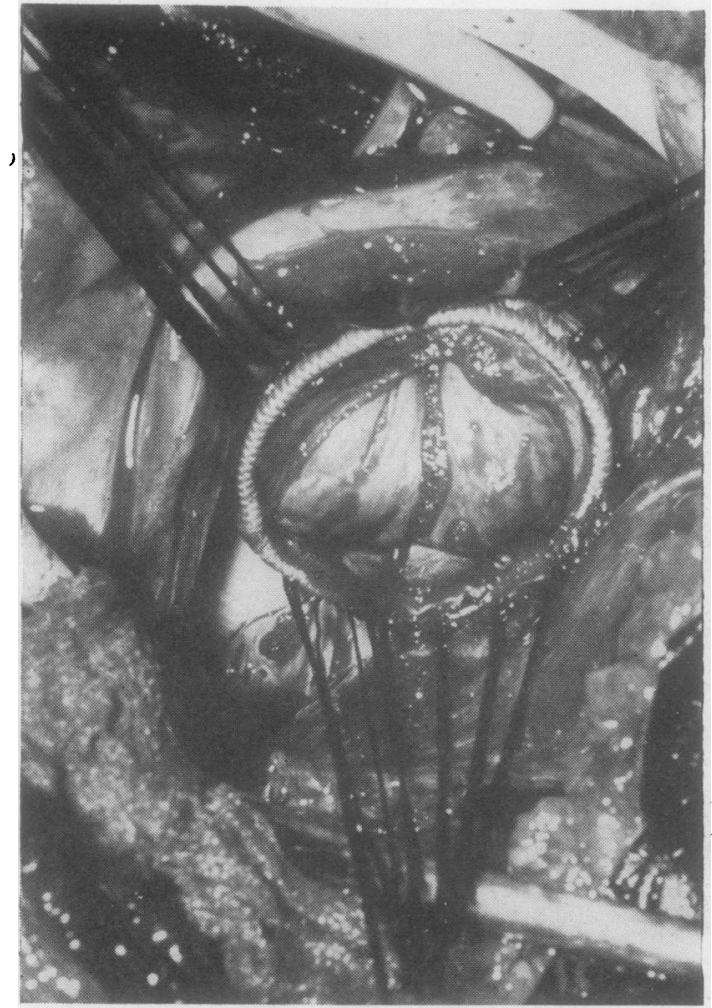

FIG. 13. Aortic graft in position inside the atrium. The interrupted stitches are passed through the mitral annulus and tied. The right coronary cusp is positioned towards the aortic part of the mitral annulus.
FIG. 14. Aortic graft in the final position above the mitral annulus. The upper part of the Teflon ring (ventricular side of the aortic graft) was secured to the atriake wall with a running suture. The valve was allowed to? become competent for a short time. 


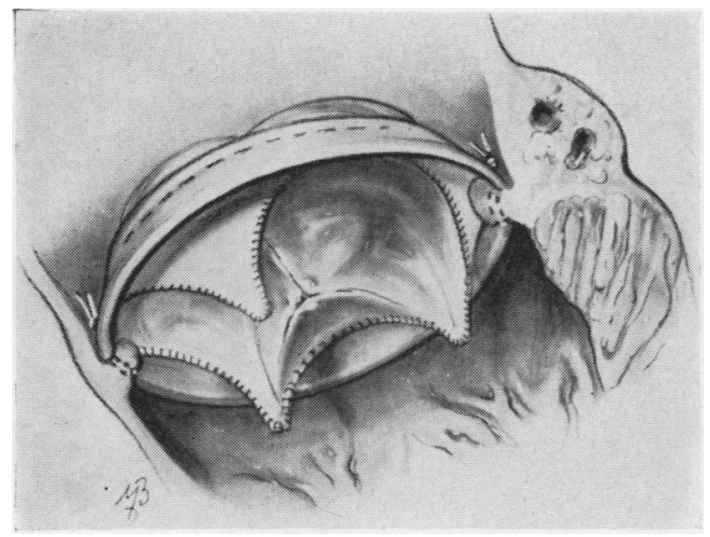

FIG. 15. Artist's view of an aortic heterograft supported with a titanium ring, inserted into the mitral annulus.

cusp, which is the largest, is directed towards the aortic part of the mitral annulus. The double needle mattress sutures previously passed through the aortic end of the prosthetic heterograft are taken separately through the mitral annulus beginning near the anterior commissure. When all these sutures are in position, the graft is lowered into the atrium and the sutures are tied and cut (Fig. 13).

While the graft is being lowered, and after this stage, care must be taken to keep the graft incompetent, otherwise air may be expelled into the aorta.

When the graft is in the correct position only about $2 \mathrm{~mm}$. projects into the ventricular cavity. The whole
Teflon tube supporting the heterograft lies in the cavity of the left atrium.

The ventricular end of the prosthetic heterograft is sutured to the auricular wall, taking care to avoid the left inferior pulmonary vein (Fig. 14). The lumen of the appendage may be closed at the same time.

2. The second type of heterograft mounted on a Dacron-covered titanium frame is sutured to the mitral annulus using a single layer of interrupted sutures which pass through the Dacron rim of the heterograft (Fig. 15).

The graft is positioned so that the two legs which support the right coronary cusp of the graft lie to each side of the root of the patient's aorta. When the graft is tied in position, the legs supporting the commissures will protrude 5 to $6 \mathrm{~mm}$. inside the ventricular cavity, whereas the ventricular end of the graft will be in the atrial cavity about 4 to $5 \mathrm{~mm}$. from the mitral annulus.

We prefer to use simple interrupted stitches for this graft rather than narrow the orifice with mattress sutures (Figs 16 and 17).

AORTIC VALVE REPLACEMENT The titanium frame covered with Dacron velour was designed for the aortic and tricuspid positions.

The prosthetic heterograft is implanted in exactly the same way as one sutures a prosthetic aortic valve; the Dacron rim of the graft provides an easy attachment for the interrupted sutures.

The inside diameter of the titanium ring should be 4 to $5 \mathrm{~mm}$. less than the inside diameter of the aortic annulus for the graft to fit properly.

The commissures should be positioned between the coronary ostia in order not to interfere with their

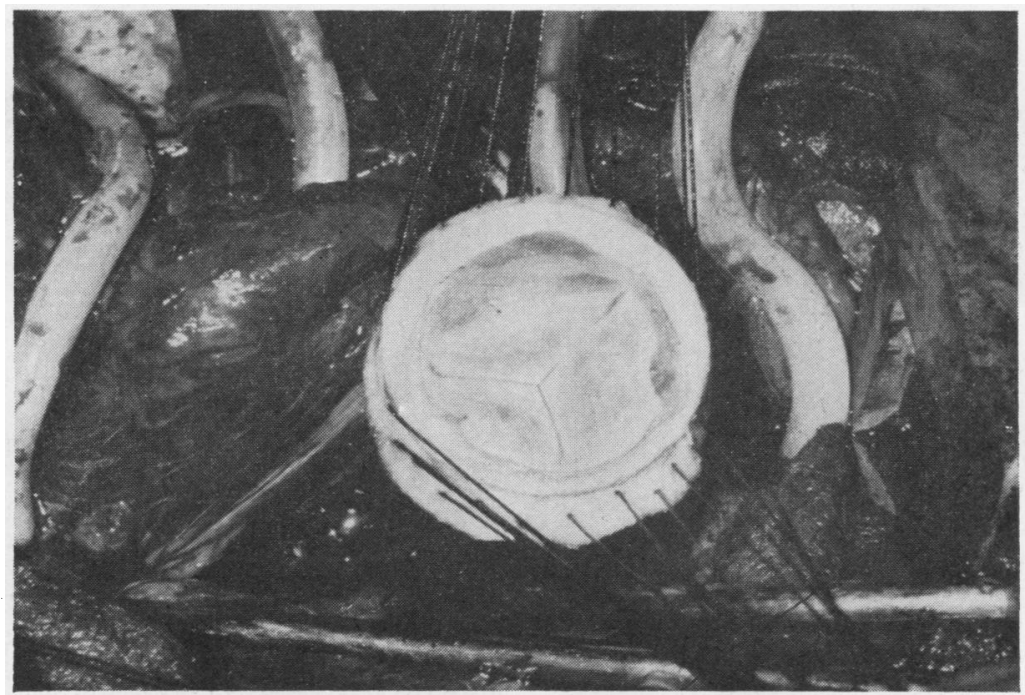

FIG. 16. Aortic graft supported with a Dacron-covered titanium ring ready to be lowered into the mitral orifice after all suturing stitches have been placed through both the mitral annulus and the Dacron rim of the graft. 


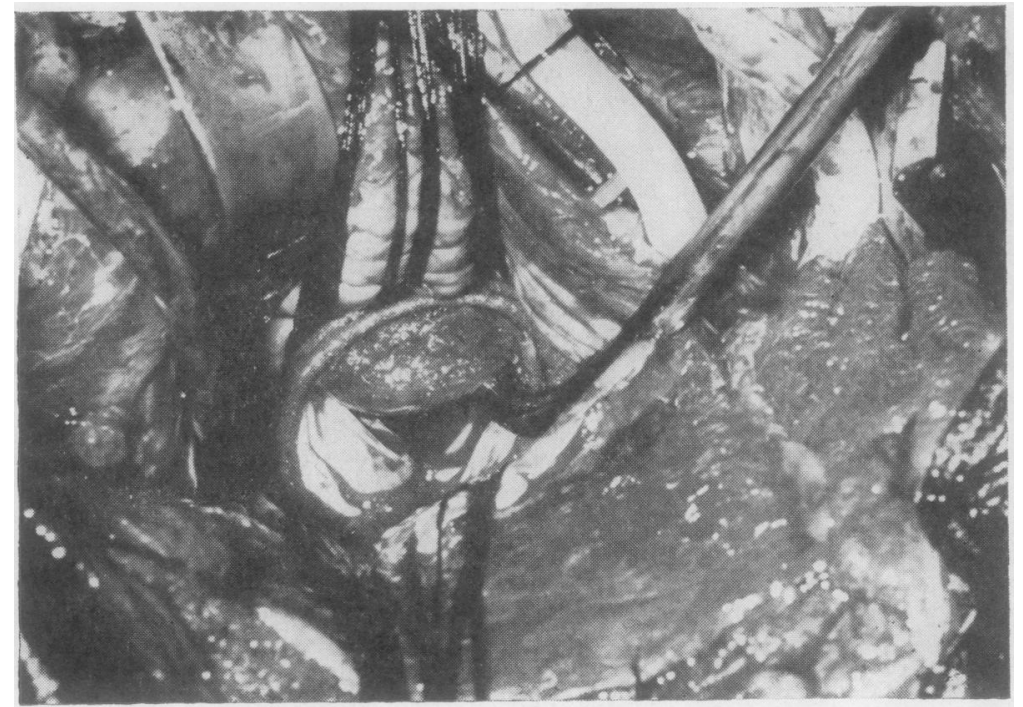

FIG. 17. Final position into the mitral annulus of the prosthetic heterograft supported with a Dacron-covered titanium ring.

openings (Fig. 18). The right coronary cusp of the graft should lie against the non-coronary cusp of the patient. The sizes of graft required for aortic replacement range from 18 to $28 \mathrm{~mm}$. internal diameter.

TRICUSPID VALVE REPLACEMENT The Dacroncovered titanium frame is ideal for this position because it does not interfere with the coronary sinus or with the opening of the inferior vena cava.

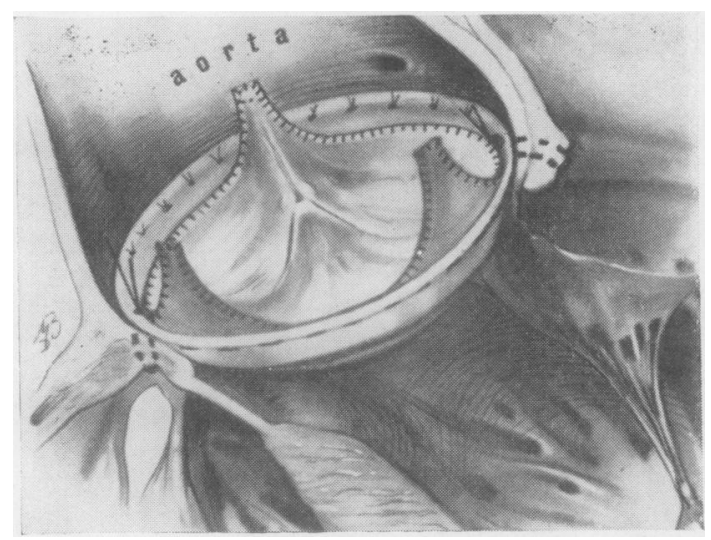

FIG. 18
The tricuspid valve is excised only if the leafleto can interfere with graft insertion, as in stenotic lesion or with graft function, as in Ebstein's anomaly. The appropriate size of graft is selected and secured i place using interrupted stitches on the posterior aspect and a continuous running suture anteriorly. The interrupted stitches are placed above and posterior to. the opening of the coronary sinus in order to avoid damage to the conduction tissue. The continuous

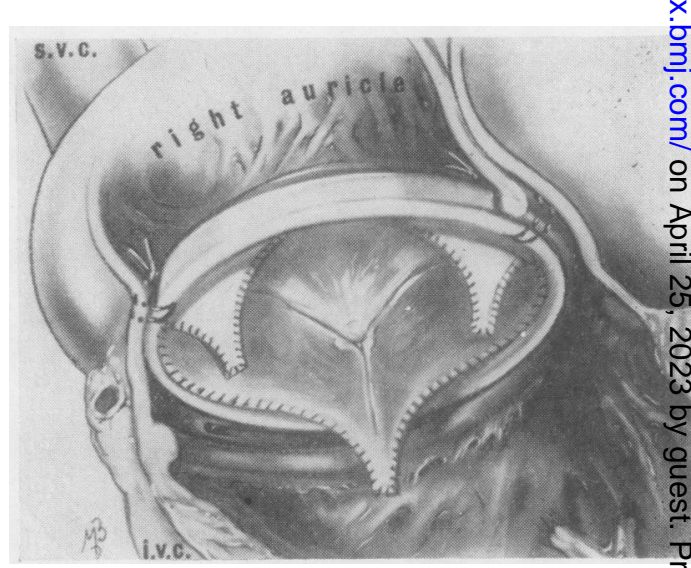

FIG. 19

FIG. 18. Artist's view of a prosthetic aortic heterograft sutured into the aortic annulus.

FIG. 19. Artist's view of a prosthetic aortic heterograft replacing the tricuspid valve. The Dacron rim of $\mathrm{D}^{2}$. graft is sutured posteriorly (above the coronary sinus opening) to the right atrial wall to avoid damage to The conduction bundle. 
suture is placed anteriorly in the true atrio-ventricular annulus. In this way the plane of the prosthetic graft is at an angle to the plane of the tricuspid annulus.

Care must be taken to position the centre of one of the aortic sinuses of the graft in relation to the opening of the coronary sinus so as not to obstruct coronary flow by one of the legs (Fig. 19).

In adults, titanium frames of 34 to $40 \mathrm{~mm}$. inside diameter are used for tricuspid replacement.

\section{CLINICAL RESULTS}

Our clinical and haemodynamic results have proved that a reconstructed, formaldehyde-preserved aortic heterograft is competent and strong enough to replace successfully the mitral, aortic, and tricuspid valves.

Anticoagulant therapy has been used during the first four to six weeks post-operatively only in patients with mitral or tricuspid replacement and atrial fibrillation. No systemic emboli have occurred. The follow-up period-up to 10 months after operation-is as yet too short to make any statement concerning the long-term function and fate of these heterografts. Speculation as to the biological implications of valve transplantation and the clinical results are reported elsewhere (Ionescu, 1968 ; Wooler and Ionescu, 1967c).

We wish to thank Miss Mary Brown, medical artist, and the staff of the Photography Department for the illustrations.

\section{REFERENCES}

Ionescu, M. I. (1968). Replacement of the mitral valve with aortic heterografts. Accepted for publication in Modern Trends in Cardiac Surgery II. Butterworths, London.

- Stoker, J. B., and Wooler, G. H. (1968). Surgical correction of Ebstein's anomaly with aortic valve heterograft. Accepted for publication in Thorax.

- Wooler, G. H., Grimshaw, V. A., and Smith, D. R. (1968). Remplacement mitral avec des hétérogreffes aortiques. Téchnique chirurgicale et résultats cliniques. Accepted for publication in Ann. Chir.

_ Smith, D. R., and Grimshaw, V. A. (1967). Mitral valve replacement with aortic heterografts in humans. Thorax, 22, 305.

Moeys, E. J., Mreyen, F. W., and Den Hartog, B. J. C. (1954). Homotransplantation of formaldehyde-preserved arteries in dogs. Arch. Chir. Neerl., 6, 333.

Wooler, G. H., and Ionescu, M. I. (1967a). Mitral valve replacement with aortic heterografts. Surgical technique and clinical results. Presented at the 8th Congress of the International Cardiovascular Society, Vienna, 9 September.

- (1967b). Aortic heterografts used clinically for replacement of the mitral valve. Presented at the Annual Meeting of the Society of Thoracic Surgeons of Great Britain and Ireland, Southampton, 21 September.

- (1967c). Mitral valve replacement with aortic heterografts. Clinical results. Presented at the Autumn Meeting of the British Cardiac Society, London, 2 November.

_ _ (1968). Aortic valve replacement with prosthetic heterografts in humans. Personal data to be published.

\section{ADDENDUM}

By the time this article was published, the total number of patients having received aortic heterografts was brought to 63 . In 48 patients the mitral valve only was replaced, in 9 the aortic valve, in 3 the mitral and tricuspid, in 2 the mitral, aortic, and tricuspid, and in 1 patient the tricuspid valve only. 